\title{
Corrosion and protection of island and offshore oil storage tank
}

\author{
Miaoke Feng ${ }^{1}$, Kaining $\mathrm{He}^{2}$ and Yanhong $\mathrm{Zhao}^{3}$ \\ ${ }^{1}$ School of petrochemical and environment, Zhejiang Ocean University, Zhoushan, Zhejiang, 311822, China \\ ${ }^{2}$ School of petrochemical and environment, Zhejiang Ocean University, Zhoushan, Zhejiang, 311822, China \\ ${ }^{3}$ School of petrochemical and environment, Zhejiang Ocean University, Zhoushan, Zhejiang, 311822, China
}

\begin{abstract}
This article is mainly based on the characteristics of the marine environment of islands and coastal seas and the current corrosion problems of storage tanks as well as their main locations, analyse the reasons for their formation and consider the potential safety hazards, so as to propose several effective storage tank corrosion protection methods, which has important positive significance for the long-term development of islands and coastal seas oil storage tanks.
\end{abstract}

\section{Introduction}

At present, there is a good development momentum for petrochemical industry in China, Considering the convenience to receive imported oil and transport oil products, more and more oil reserve bases are built in the coastal areas or on some islands in China, such as Zhenhai Refining and Chemical Base in Ningbo, Zhejiang, and Aoshan National Oil Reserve Base in Zhoushan, Zhejiang, since the weather condition on the coastal and island is with rich rainfall and high water content with salt particle and halogen ions (especially the chloride ion) in the air, the salt particle will be easyto stick on oil tank, and make the oil tank wall corroded, finally will cause the tiny crack onthe oil tank wall, if there is tiny crack on the oil tank wall, it is likely to cause serious safety accidents, therefore improving anti-corrosion ability to maintain the oil tank under good condition is very urgent and necessary.

\section{Analysis of island and coastal environment}

In the course of the hydrological cycle, a large amount of water enters the atmosphere from the sea, carrying with it a large number of halogen ions (this article mainly discusses the effects of chloride ions) and solid salt particles, which form a salt spray that, when transported by the wind, accumulates in depressions in the tank roof, in weld seams and even in the tank floor through the tank drainage holes, forming an aqueous solution containing a large number of halogen ions. In addition, the coastal and island areas have strong winds, often typhoons and other attacks, salt particles and some other solid particles with the wind constantly hit the tank wall, which will also to some extent lead to the tank wall paint and other protective layer off, making the steel local area directly exposed to the atmosphere in contact with oxygen and accelerated corrosion; Moreover, the coastal soil near the loose, low resistivity of the soil, salt content is very high, so in the tank, the temperature of the soil is very low. The substrate area can easily become an electrochemically corrosive environment; this, together with the high air flow, results in a huge difference in airflow between the outside and the inside of the tank, leading to a huge difference in oxygen concentration between the two sides, which is an excellent environmental condition for the formation of an oxygen concentration differential cell.

\section{The main corrosion parts of islands and coastal storage tanks.}

In the case of the Gangpu oil depot in Sinopec Zhoushan Oil Company, for example, the main areas of corrosion found during overhauls in 2000, 2009 and 2012 were the peeling of the paint on the tank walls, the welded seams of the connecting parts, the areas where water had accumulated due to depressions from external forces and the bottom plates of the storage tanks.

\subsection{Corrosion at the tank wall}

As the tanks are located in the marine atmosphere, their outer walls are often in contact with rainwater or moist air. In Zhoushan, for example (according to the Zhoushan Meteorological Station, the number of windy days per year is 23.7 days in Dinghai, 44.4 days in Putuo, 87.5 days in Daishan and 125.9 days in Shengsi), the windy days are several months a year on average, and the salts and solid particles carried by the wind will affect the paint applied to the tank walls. In addition, the chlorine ions in the atmosphere will accelerate corrosion and form pits. As time goes by, the exterior paint will peel off over a large area, which will eventually lead to complete corrosion of the outer wall of the tank.

Although the tank walls are not in contact with the 
atmosphere and thus avoid atmospheric corrosion, the oil stored in the tank, the water at the bottom and the air on the surface of the oil, because they contain different amounts of oxygen, tend to form an oxygen concentration differential cell on the contact surface, which is an important cause of localised corrosion of the tank walls, with the higher oxygen concentration at the cathode and the lower oxygen concentration at the anode. The corrosion rate of the inner wall of the tank varies depending on the oil it contains. The rate of internal corrosion varies depending on the product being stored in the tank. In carbon steel, for example, the rate of internal corrosion is much greater in tanks for petrol than in tanks for diesel and lubricating oil.

\subsection{Corrosion on tank bottoms and weld seams}

The high atmospheric moisture content of islands and coastal environments, the humid air, the formation of salt spray, the abundance of precipitation and the porous soils of coastal areas with their high electrical conductivity and salt content are conditions that tend to create an electrochemically corrosive environment at the floor of the storage tanks. Coupled with the extremely frequent sea breezes in coastal reservoirs, the speed and volume of atmospheric circulation is high, making it easy to form an oxygen concentration differential corrosion cell between the outer side of the tank bottom and the base layer of the tank bottom and causing corrosion damage. In order to prevent the upward encroachment of groundwater in the tank area and the effects of high tides on the tanks, asphalt sand bedding is laid on the base of the tank bottom during construction, thus slowing down the corrosion of the bottom slab. However, oil storage bases on islands and in coastal areas are often tasked with distributing oil to the inland and receiving imported oil from overseas, so their tanks are often in alternating full and empty conditions, resulting in frequent changes in the forces on the tank base. This causes corrosion. In addition, rainwater will entrain the salt ions in the air along the drainage pipe and accumulate on the tank bottom plate from the top of the tank and the floating tray, forming an electrolyte solution containing high concentrations of halogen ions (especially chloride ions) over time.

The stress concentration at the weld, the fact that the surface does not remain highly flat like other parts of the weld, the different materials of the electrode and the weld, and the multiplicity of moisture, oxygen and halogen ions make this area highly susceptible to corrosion damage, mainly in the form of selective corrosion, intergranular corrosion and crevice corrosion.

\subsection{The connection between the outer edge plate of tank bottom and foundation}

There are several reasons for the corrosion here: firstly, the radial expansion of the bottom plate due to changes in ambient temperature, and secondly, the deformation of the tank due to changes in the amount of oil stored in the tank, which causes significant cyclic stresses upon reception of the oil in the tank. Deformation; when oil is dispensed from a tank, the tank is returned to its original state, but the edge plate is warped upwards due to plastic deformation, thus creating a gap between the edge plate and the tank base. This gives a good opportunity for corrosive media such as rainwater and salts to enter the gap, and because the gap is small, the long-term presence of these corrosive media in the gap and the formation of an electrolyte solution provides perfect environmental conditions for the electrochemical corrosion of carbon steel, which can eventually lead to severe bottom plate corrosion and perforation day after day, which is extremely dangerous for safe production in the reservoir.

\section{Type and mechanism of tank corrosion}

The main types of corrosion that occur in storage tanks on islands and coastal areas are electrochemical corrosion, which includes crevice corrosion, pitting corrosion, selective corrosion and intergranular corrosion. Electrochemical corrosion is the corrosion caused by the reaction of metals in an electrolyte solution to form a cell. The contact of impure metals with the electrolyte causes an electrochemical reaction to take place, in which the more active metals are oxidised. The corrosion process of a storage tank made of carbon steel will generally take place as follows: the anode, which acts as an electrochemical reaction, loses electrons and becomes divalent iron ions, while the cathode gains electrons as hydrogen ions and produces hydrogen gas.

\subsection{Oxygen concentration cell}

This macroscopic corrosion cell occurs mainly on the underside of the tank floor, in the tank wall panels. It is formed by contact between the tank's constituent material, carbon steel, and a solution with a different oxygen content and is also known as an uneven-filling cell. Immersion of the carbon steel in a neutral solution containing oxygen results in the formation of an oxygen electrode, and the following reactions take place:

$$
\mathrm{O}_{2}+2 \mathrm{H}_{2} \mathrm{O}+4 e^{-} \rightarrow 4 \mathrm{OH}^{-}
$$

Its electrode potential is related to the partial pressure of the oxygen. The higher the partial pressure, the higher the electrode potential will be, so it will have a certain potential difference depending on the concentration of oxygen in the medium, and the lower potential area will be corroded as the anode. In coastal areas, tank foundations are often treated harshly in order to prevent the influence of the water table, etc. on the tank bottom. This makes it extremely difficult to replenish oxygen at the tank floor, which is therefore susceptible to severe corrosion and perforation of the floor due to the formation of an oxygen concentration cell. Likewise, on the inside of the tank walls, oxygen concentration varies depending on the oil in contact, the water on the bottom, the oxygen concentration at the upper air interface and the difficult oxygen replenishment areas at component joints, which are also susceptible to the formation of differential oxygen 
cells.

\section{2 pitting}

One of the important conditions for the pitting of passivated metals is the presence of reactive anions (e.g. chloride ions) in the electrolyte solution, and the abundance of chloride ions in the atmosphere on islands and in sea-side environments contributes to the corrosion. The active anions preferentially attach themselves to defective locations on the surface of the passivated metal, e.g. the halogen ions of the chloride ions accelerate the destruction of the passivated film at a rate much faster than the repair of the passivated film, thus forming a 'nucleus' which, if not removed in time, pitting corrosion will further develop into visible corrosion holes in the metal surface. The next stage is the formation of an occluded cell inside the pore, which is caused by the passivated state of the metal outside the pore and the activated state inside the pore, where substances such as rust from corrosion adhere to the pore and cause the electrolyte in the pore to be retained. As the corrosion continues, more and more metal ions are present inside the pore, which attracts anions (mainly chloride ions) from outside the pore to the pore where hydrolysis occurs, increasing the acidity and accelerating the corrosion, and eventually the pore progresses downwards to form a perforation by gravity.

\subsection{Gap corrosion}

Crevice corrosion mainly occurs in extremely small gaps (between approx. $0.025-0.1 \mathrm{~mm}$ ) that form between metal parts and metal parts or between metal parts and non-metal parts. In the early stages of corrosion, ordinary electrochemical corrosion occurs mainly in this area, i.e. the metal is ionised as an anode and oxygen is reduced as a cathode. When the oxygen in the crevices is consumed, the reduction of oxygen ceases and there is still plenty of oxygen outside the crevices. (autocatalytic occlusion of the cell) The crevice corrosion increases with the passage of time.

\subsection{The corrosion effect of chlorine ion on carbon steel}

The corrosion products of carbon steel in the electrolyte solution of chloride ions are mainly composed of $\gamma$ $\mathrm{FeOOH}, \alpha-\mathrm{FeOOH}, \mathrm{Fe} 3 \mathrm{O} 4$ and a small amount of $\beta$ $\mathrm{FeOOH}$, of which $\mathrm{Fe} 3 \mathrm{O} 4$ and $\alpha-\mathrm{FeOOH}$ are produced at the fastest rate, but their crystal structure is loose, large particles, showing honeycomb or fluffy, so the resulting rust layer does not have a protective effect and is easy to fall off.

\section{Corrosion protection measures for storage tanks}

\subsection{Coating protection}

Anticorrosive coatings have a long history and are widely used for tank corrosion protection because of their protective effect, ease of application and costeffectiveness. Anti-corrosion coatings can be broadly divided into metallic and non-metallic coatings, which separate the metal from the corrosive medium to prevent electrochemical reactions from occurring and provide excellent corrosion protection as long as the coating is intact [5]. In consideration of economy, the more suitable coatings for tanks are: primer: epoxy zinc rich (two coats); intermediate paint: chlorinated rubber (one coat); topcoat: chlorinated rubber topcoat (two coats), the thickness of which must not be less than $200 \mu \mathrm{m}$ after the coating has dried.

\subsection{Impressed current cathodic protection}

If the tank is protected by the coating alone, then when the coating partially falls off or a small area is damaged, it will not protect the tank from local corrosion such as pitting, but will accelerate the corrosion process and cause more damage to the tank, so the coating protection can be taken at the same time using an external current cathodic protection method, the combination of the two can more effectively and reasonably achieve the purpose of corrosion protection of the outer wall of the tank.

External current cathodic protection is a method in which a direct current supply is strung into the current circuit and the DC current is passed through an auxiliary anode to the metal to be protected, thus making the metal to be protected the cathode for the purpose of protection. It has the following advantages: a high driving voltage, the ability to control the cathodic protection current output can be varied flexibly over a wide range, which makes it suitable for large tanks; it is also suitable for use in harsh corrosive conditions or high resistivity environments; and it provides more complete cathodic protection for exposed metals.

\subsection{Cathodic protection of sacrificial anode}

Cathodic protection at the expense of anode is using a metal or alloy with a lower potential than the metal to be protected as the anode to protecting the metal as a cathode. The two form a corroded primary cell. The anode is consumed by corrosion instead of the cathode. It has the following advantages: inexpensive, easy to install, easy to construct and easy to use, high drive voltage to metal, low impact on surrounding metal and no maintenance required. All we need to do is to place a few zinc blocks on the bottom plate of the tank after it has been built to effectively protect it from corrosion. 


\section{Conclution}

List the locations where corrosion occurs, the types of

Table 1. A table of corrosion locations, mechanisms and protective measures

\begin{tabular}{|c|c|c|}
\hline Location of corrosion & Corrosion mechanisms & Protective measures \\
\hline At the tank walls & Oxygen densitometry cells & Coating Protection \\
\hline Tank bottoms and welded seams & Pitting & External current cathodic protection \\
\hline \multirow{2}{*}{$\begin{array}{l}\text { The connection of the outer edge } \\
\text { plate of the tank bottom to the } \\
\text { foundation }\end{array}$} & Crevice erosion & $\begin{array}{l}\text { Cathodic protection of sacrificial } \\
\text { anodes }\end{array}$ \\
\hline & $\begin{array}{l}\text { Corrosion effects of chloride ions on } \\
\text { carbon steel }\end{array}$ & - \\
\hline
\end{tabular}

\section{References}

1. $\mathrm{Xu} \mathrm{T}$, Yue L.(2009), Impressed current cathodic protection of large crude oil storage tank [J] Gansu science and technology,25(23):27-28.

2. Chen H, Li X, Wei Y.(2007), Study on corrosion mechanism of carbon steel containing chloride ions in environment $[\mathrm{J}]$.Corrosion and protection,(1):17-19.

3. Wang X.(2007) Stress corrosion of stainless steel by halogen ion $[\mathrm{J}]$.Chemical engineering and equipment, (10): 174-176.

4. Gao D, Yu H, Zhou Y, etc.(2014),Analysis on corrosion and protection of oil tank in island environment [J]. Sichuan Chemical Industry, 17(3): 30-33.

5. Bai P, Song S, Zou Z, etc.(2015) Corrosion and protection of metals in marine environment [J].Shanxi chemical industry, 2015, 35(5):28-29, 45. corrosion and the methods of protection in the following table. 